ISSN: 0213-2087 e-ISSN: 2444-7080

DOI: https://doi.org/10.14201/shhcont382020295324

\title{
EL REGISTRO DE EMPRESAS EDITORIALES: \\ LA CENSURA EN LA LEY DE PRENSA \\ E IMPRENTA DE $1966^{1}$
}

\section{The Register of Publishing Companies: the censorship in the Press and Printing Act of 1966}

\author{
Carlota ÁLVAREZ MAYLÍN \\ Consejo Superior de Investigaciones Científicas (CSIC, España) \\ carlota.alvarez@cchs.csic.es \\ https://orcid.org/0000-0003-3516-8949
}

Recibido: 11/09/2019 Revisado: 13/05/2020 Aceptado: 12/06/2020

RESUMEN: El Registro de Empresas Editoriales fue una de las herramientas de censura editorial que impulsó el Régimen franquista en su intento por frenar la influencia que los editores, como agentes culturales con incidencia política, tuvieron sobre la sociedad española durante la década de los sesenta y setenta. La ley de Prensa e Imprenta de 1966 establecía la obligación de inscribir todas las editoriales en un Registro controlado por el Ministerio de Información y Turismo. A pesar de la apariencia liberalizadora que el Régimen intenta darle, esta ley pone el foco de la represión cultural sobre los productores del libro: los editores y las editoriales. Los archivos del Registro de Empresas Editoriales se conservan en el Archivo General de la Administración (AGA), cuya documentación es imprescindible para la comprensión del desarrollo del mundo editorial desde 1966 hasta principios de los años ochenta. Este artículo estudia el caso de las editoriales que formaron parte de la Distribuidora Enlace, cuyos expedientes muestran un amplio abanico de las tipologías que se pueden encontrar en este Registro.

Palabras clave: censura; políticas editoriales; Registro de Empresas Editoriales; Distribuidora Enlace.

1. Esta publicación es el resultado de una investigación financiada por el MINECO a través de un contrato para la Formación del Personal Investigador (FPI2017) y por el proyecto «Prácticas culturales y esfera pública: editoras españolas y latinoamericanas contemporáneas» (FFI2016-76037-P). 
ABSTRACT: The Register of Publishing Companies was one of the tools of editorial censorship that was promoted by the Francoist regime in its effort to control the influence that publishers, as cultural agents with political impact, had on the Spanish society during the sixties and seventies. The Press and Printing Act of 1966 established the obligation to register all publishing companies in a Register managed by the Information and Tourism Ministry. Despite the liberalizing appearance, this regulation focused the cultural repression on book producers: the publishers and the publishing companies. The documentation related to Register of Publishing Companies is preserved in the Spanish Administration Archives and its study allow us to understand the process of development suffered by the publishing industry from 1966 to the early eighties. This article examines the study case of publishing houses that were part of Enlace Distributor, whose files show almost all typologies that we can find in this Register.

Key words: censorship; editorial policies; Register of Publishing Companies; Enlace Distributor.

Avanzada la década de los años sesenta, casi treinta años después de la Guerra Civil, seguía vigente en España la Ley de Prensa de 22 de abril de 1938², vinculada al Código Militar e inspirada en los modelos de propaganda de los fascismos europeos 3 . Esta vetusta ley establecía un extraordinario control político de la información ${ }^{4}$ como mecanismo imprescindible para una dictadura que se fundamentaba en la exclusión del contrario y en la desaparición de sus ideas5. El mundo del libro se regía por el Instituto Nacional del Libro Español, institución creada en agosto de 1935 durante el periodo republicano ${ }^{6}$ y recuperada por el franquismo ${ }^{7}$, con el objetivo de tutelar económica y culturalmente el mercado de las letras ${ }^{8}$. El INLE tuvo que lidiar con el bloqueo al que estaba sometida la industria editorial española, víctima de la penuria económica, la falta de intervención del Estado y el exilio de los principales intelectuales del mundo literario?.

2. BOE, 23 de abril de 1938, n. 549, p. 6915; Justino Sinova, en su obra La censura de prensa durante el franquismo (Barcelona: Random House Mondadori, 2006) hace un extenso análisis sobre la Ley de Prensa de 1938 y sus consecuencias.

3. Molinero, César: La intervención del Estado en la prensa. Barcelona: Editorial Dopesa, 1971, p. 9.

4. De Diego González, Álvaro: «La prensa y la dictadura franquista. De la censura al 'Parlamento de papel'», Conferencia - Debate, Universidad de Málaga, 2016, p. 2. http://hdl.handle.net/10630/11297

5. Reflexionan sobre la censura y las herramientas de control del mundo editorial desde la perspectiva más inmediata en el tiempo Cisquella, Georgina; Erviti, José Luis y Sorolla, José A.: La represión cultural en el franquismo. Diez años de censura de libros durante la Ley de Prensa (1966-1976). Barcelona: Anagrama, 2002, pp. 19-20.

6. Durante el período republicano adquirió el nombre de Instituto del Libro Español y se regía por el Ministerio de Instrucción Pública.

7. Orden de 23 de mayo de 1939, Ministerio de la Gobernación. BOE de 24 de mayo de 1939.

8. Ruiz BAUTISTA, Eduardo: Los señores del libro: propagandistas, censores y bibliotecarios del primer franquismo. Gijón: Editorial Trea, 2005, p. 241.

9. SÁNChez Vigil, Juan Miguel: La edición en España. Industria cultural por excelencia. Historia, proceso, gestión, documentación. Gijón: Editorial Trea, 2009, p. 103 estudia el INLE como institución rectora de la política del libro durante el periodo franquista.

(C) Ediciones Universidad de Salamanca / CC BY-NC-ND Stud. hist., H. ${ }^{a}$ cont. 38, 2020, pp. 297-326 
Durante la década anterior, el franquismo comenzó a realizar cambios en su estructura económica con el objetivo de superar el régimen autárquico y abrirse a una economía capitalista competitiva, cambiando su base socioeconómica y diversificando su producción ${ }^{10}$. Esta estrategia de cambio quedó reflejada en el Plan de Estabilización de 1959, un intento de apertura económica que tenía como fin alcanzar una mayor homologación internacional. Las consecuencias más directas fueron el éxito económico y el surgimiento de las clases medias, que chocaron frontalmente con el proteccionismo cultural mantenido por el ministro del Régimen, Arias Salgado ${ }^{11}$. En los años sesenta estas contradicciones se fueron haciendo más evidentes, durante 1962 tuvo lugar una de las crisis políticas más graves del Régimen franquista: las grandes huelgas obreras durante la primavera, las movilizaciones universitarias, las reuniones en Múnich de la oposición democrática y las reivindicaciones nacionalistas en Cataluña y el País Vasco, pusieron de manifiesto la fuerte discordancia que existía entre la ideología proyectada desde el Estado franquista y los sectores organizados de la sociedad española ${ }^{12}$.

El 10 de julio de 1962, con el objetivo de impulsar una política desarrollista en el plano económico y reformas liberales en el plano político, se formó un nuevo gobierno en el que las carteras económicas recayeron en manos de los tecnócratas del Opus Dei y el Ministerio de Información y Turismo quedó en manos de Manuel Fraga Iribarne ${ }^{13}$. Aparentemente, este cambio supuso el triunfo de las posiciones más reformistas del espectro político del Régimen frente al inmovilismo de Falange ${ }^{14}$.

1. La ley de Prensa e Imprenta de 1966, un cambio en los mecanismos de CONTROL

Los cambios cualitativos en los modos de pensar generaron la reclamación de mayores cuotas de libertad, que aumentaron la oposición interna. Se produjo un periodo

10. Carrillo, Marc: «El marco jurídico - político de la libertad de prensa en la Transición a la democracia en España (1975-1978)", Historia Constitucional, 2, 2001, pp. 1-42, p. 4, analiza el contexto económico y su desarrollo durante el periodo. http://www.historiaconstitucional.com/index.php/historiaconstitucional/ article/view/119/103

11. Cisquella, Georgina; ERviti, José Luis y SOROLla, José A.: La represión cultural en el franquismo..., p. 25; MenChero De los Ríos, Carmen: «La modernización de la censura: la Ley de 1966 y su aplicación». En: Martínez Martín, Jesús A.: Historia de la edición en España 1939-1975. Madrid: Marcial Pons, 2015, pp. 67-96, p. 67.

12. Cisquella, Georgina; ERviti, José Luis y SOROLla, José A.: La represión cultural en el franquismo..., p. 25 reflejan cómo el contexto vigente obligó al Régimen a realizar cambios que contentarán ideológicamente a las capas de la sociedad que habían resultado beneficiarias de los cambios y éxitos económicos

13. Ibidem.

14. Gubern, Román: La censura. Función política y ordenamiento jurídico bajo el franquismo (19361975). Barcelona: Ediciones Península, 1981, p. 181. 
de descontento y cuestionamiento de la legitimidad del Régimen ${ }^{15}$. Las aspiraciones de la burguesía liberal, surgida durante el éxito económico, de alcanzar una revolución democrático - burguesa quedaron truncadas cuando el aperturismo económico no fue acompañado de un cambio en el orden político. Los hechos que marcaron este periodo fueron: la ejecución de Julián Grimau el 20 de abril de 1963, la ejecución de dos militantes anarquistas mediante el garrote vil el 27 de agosto de 1963 y la creación del Tribunal de Orden Público el 2 de diciembre de $1963^{16}$.

En el campo de la industria editorial, los editores se vieron beneficiados por el I Plan de Desarrollo Económico y Social (1964-1967) ${ }^{17}$, que incluía al sector del libro como prioritario en la recepción de ayudas y con beneficiosas ventajas fiscales y crediticias. Asimismo, en 1964 salió a la luz la Ley de Reforma Universitaria, que trajo consigo un aumento en la producción de libros $^{18}$. Los cambios en el ámbito editorial tuvieron importantes consecuencias: la masificación de la lectura, el aumento de la presencia del libro en espacios domésticos, la elaboración de nuevos temas, el surgimiento de una generación de nuevos autores y la producción de nuevos formatos de libros, hechos que significaron una renovación de la oferta cultural ${ }^{19}$.

Aprovechando el contexto, el ala más renovadora del franquismo, aupada por los éxitos económicos, defendió una mayor apertura con el objetivo de garantizar la continuidad del franquismo como sistema. El Régimen debía adaptarse a la realidad social canalizando ciertas demandas sociales y realizando cambios que no comprometieran la esencia misma del franquismo ${ }^{20}$.

Revisar la Ley de Prensa de 1938 era una necesidad acuciante que se discutía desde $1945^{21}$. A su llegada al Ministerio de Información y Turismo, Fraga asumió el compromiso de liberalizar la prensa, proyectando una nueva ley de Prensa e Imprenta, cuyo proceso de creación fue lento debido a la oposición interna y de la Iglesia ${ }^{22}$. Pío Cabanillas, subsecretario del Ministerio, fue el encargado de la redacción del texto,

15. Martínez Martin, Jesús A.: Historia de España, siglo XX, 1939-1996. Barcelona: Crítica, 1999.

16. Estos hechos mancharon la imagen de aperturismo que el Régimen buscaba proyectar, tal y como señala Gubern, Román: La censura. Función política..., p. 183.

17. BOE, 30 de diciembre de 1963, n 312, pp. 18190-18198.

18. Sánchez Vigil, Juan Miguel: La edición en España..., p. 120 y Martínez Martín, Jesús A.: «El capitalismo de edición moderno. Las empresas editoriales: negocios, política y cultura. Los años sesenta». En: Martínez Martín, Jesús A.: Historia de la edición en España 1939-1975. Madrid: Marcial Pons Historia, 2015, pp. 273-328, aprecian la importancia que tuvieron los cambios legislativos de la década de los sesenta para la industria del libro.

19. Menchero de los Ríos, Carmen: La modernización de la censura..., p. 68.

20. Menchero de los Ríos, Carmen: La modernización de la censura..., p. 69.

21. MuÑoz SORO, Javier: "Vigilar y censurar. La censura editorial tras la Ley de Prensa e Imprenta». En: Ruiz BAutista, Eduardo (coord.): Tiempo de censura. La represión editorial durante el franquismo. Gijón: Trea, 2008, pp. 111-142, p. 115 refleja la situación de los periodistas y editores ante tales procesos burocráticos.

22. De Diego González, Álvaro: La prensa y la dictadura franquista ..., p. 9. 
cuyo primer borrador se presentó en $1964^{23}$. La presentación del texto definitivo se dilató hasta dos años más tarde ${ }^{24}$. El 15 de marzo de 1965 se aprobó en Cortes con tan sólo tres votos en contra, y el 19 del mismo mes se publicaba en el BOE para entrar en vigor el 8 de abril ${ }^{25}$.

En el primer borrador de 1964, ya se intuían los ejes básicos del texto: la formalización de la libertad de prensa, la supresión de la censura previa, la creación de un registro oficial de empresas periodísticas y editoriales, y la libre designación de directores $^{26}$. Este último punto es relevante pues estaba condicionado por la Ley de 25 de agosto de 1939 sobre nombramientos de Consejeros, Directores y Gerentes de Sociedades Anónimas ${ }^{27}$, según la cual todas las empresas que tuvieran un capital de más de 5 millones de pesetas, o fueran concesionarias de obras o servicios públicos, o se dedicasen a la producción de elementos específicos de la defensa nacional, o fuesen sociedades de crédito ${ }^{28}$, debían elevar sus propuestas de designaciones al Gobierno, el cual las aprobaría si consideraba que las personas propuestas reunían las condiciones de moralidad pública y adhesión al Régimen indispensables para el ejercicio de los $\operatorname{cargos}^{29}$. El objetivo de Fraga era adecuar la política informativa y cultural a las demandas de la sociedad española y superar gradualmente las condiciones informativas que se generaron durante la posguerra ${ }^{30}$. En sus memorias, Fraga relata que la Ley de Prensa de 1938 había conseguido hacer compatible la libertad de las empresas dedicadas a la información y la intervención del Estado, y que la Ley de 1966 buscaba adecuarse a los nuevos tiempos, estableciendo un nuevo derecho a la información que fuese benigno para el conjunto de la población y que limitase las posibilidades de cometer ilegalidades ${ }^{31}$. La ley se presentó como la superación del dirigismo cultural y supuso un atisbo de apertura, pero sin cambios en las raíces del Régimen. Buscaba canalizar

23. Chulí́ Rodrigo, Elisa: El poder y la palabra: prensa y poder político en las dictaduras. El régimen de Franco ante la prensa y el periodismo. Madrid: UNED, Biblioteca Nueva, 1999, p. 210.

24. Dueñas, Gonzalo: La ley de Prensa de Manuel Fraga. Francia: Ruedo Ibérico, Colombes, 1969, pp. 61-62. Se sucedieron hasta cuatro borradores antes de que saliera a la luz el que fue presentado en el Pleno de las Cortes, De Diego González, Álvaro: La prensa y la dictadura franquista..., p. 9.

25. BOE, 19 de marzo de 1966, n 67, pp. 3310-3315

26. Estos ejes se van a ver reflejados en el prólogo de la ley, Menchero DE Los Ríos, Carmen: $L a$ modernización de la censura..., p. 69.

27. BOE, 1 de septiembre de 1939, n 244, p. 4856.

28. Artículo 1, Ley de 25 de agosto de 1939 sobre nombramientos de Consejeros, Directores y Gerentes de Sociedades Anónimas.

29. Artículo 2, Ley de 25 de agosto de 1939 sobre nombramientos de Consejeros, Directores y Gerentes de Sociedades Anónimas.

30. Cisquella, Georgina; ERviti, José Luis y SoRolla, José A.: La represión cultural en el franquismo..., p. 25 .

31. Fraga Iribarne, Manuel: Memoria breve de una vida pública. Barcelona: Planeta, 1980. 
las aspiraciones de la pequeña burguesía crítica y crear un nuevo marco legal de referencia para periodistas y editores ${ }^{32}$ :

Los cuerpos legales donde en la actualidad se encuentra contenido, en nuestra Patria, el ordenamiento jurídico de la Prensa y la Imprenta están constituidos fundamentalmente por la Ley de veintiséis de junio de mil ochocientos ochenta y tres y la de veintidós de abril de mil novecientos treinta y ocho. La mención de estas fechas pone de relieve la necesidad de adecuar aquellas normas jurídicas a las actuales aspiraciones de la comunidad española y a la situación de los tiempos presentes ${ }^{33}$.

El prólogo de la Ley de Prensa e Imprenta es revelador para entender el propósito de esta ley. Es un intento de "normalización» del franquismo, buscaba abandonar la vieja imagen de excepcionalidad que representaba la ley de 1938, para regularizar las actuaciones gubernamentales de control mediante la legalidad ordinaria ${ }^{34}$.

Al emprender decididamente esta tarea, el Gobierno ha cumplido escrupulosamente su papel de fiel intérprete del sentir y del pensar del país, con el rigor y el estudio que deben ineludiblemente preceder a la redacción de todo texto legislativo que quiera nacer con una pretensión no sólo de viabilidad, sino también de fijeza y de permanencia. Por ello, la estructura básica y los muros maestros del sistema jurídico que con la presente Ley se trata de instaurar no han sido configurados sino después de ponderar, en la forma más equilibrada posible, los diversos factores y las diversas fuerzas e intereses que en la realidad social regulada entran en juego ${ }^{35}$.

La Ley se inspiraba doctrinalmente en el Concilio Vaticano II y en el reconocimiento de la libertad de expresión del Fuero de los Españoles ${ }^{36}$. Encontramos en este prólogo un lenguaje bastante novedoso con dos ideas importantes, el desfase del aparato legal respecto a la realidad nacional e internacional, y la necesidad de canalizar los intereses y aspiraciones de los nuevos grupos sociales surgidos tras el éxito económico.

Justifican tal necesidad el profundo y sustancial cambio que ha experimentado, en todos sus aspectos, la vida nacional, como consecuencia de un cuarto de siglo de paz fecunda; las grandes transformaciones de todo tipo que se han ido produciendo en el ámbito internacional; las numerosas innovaciones de carácter técnico surgidas en la difusión impresa del pensamiento; la importancia, cada vez mayor, de los medios informativos poseen en relación con la formación de la opinión pública, y, finalmente, la conveniencia

32. Discurso de M. Fraga Iribarne en la sesión del día 15 de marzo de 1966, incluido en el volumen Prensa e Imprenta de la colección "Textos Legales» del "Boletín Oficial del Estado".

33. Prólogo de la Ley 14/1966, de 18 de marzo, de Prensa e Imprenta.

34. Chulí́ Rodrigo, Elisa: El poder y la palabra...

35. Prólogo de la Ley 14/1966, de 18 de marzo, de Prensa e Imprenta.

36. La libertad de expresión venía recogida como un derecho en el artículo 12 del Fuero de los Españoles, CARrillo, Marc: El marco jurídico-político de la libertad de prensa ..., p. 5. 


\section{CARLOTA ÁLVAREZ MAYLÍN \\ EL REGISTRO DE EMPRESAS EDITORIALES: LA CENSURA EN LA LEY \\ DE PRENSA E IMPRENTA DE 1966}

indudable de proporcionar a dicha opinión cauces idóneos a través de los cuales sea posible canalizar debidamente las aspiraciones de todos los grupos sociales, alrededor de los cuales gira la convivencia nacional ${ }^{37}$.

La Ley de Prensa e Imprenta estaba formada por 72 artículos, cuatro disposiciones finales, cinco disposiciones transitorias y una disposición derogatoria de la Ley de 1938. En el artículo 1 — titulado "Libertad de expresión por medio de impresos»— se reconocía el derecho a expresar libremente el pensamiento ${ }^{38}$, plasmado anteriormente en el Fuero de los Españoles ${ }^{39}$. Sin embargo, la libertad que afirmaba el artículo 1, se limitaba en el artículo 2:

La libertad de expresión y el derecho a la difusión de informaciones, reconocidas en el artículo primero, no tendrán más limitaciones que las impuestas por las leyes. Son limitaciones: el respeto a la verdad y a la moral; el acatamiento a la Ley de Principios del Movimiento Nacional y demás Leyes Fundamentales; las exigencias de la defensa Nacional, de la seguridad del Estado y del mantenimiento del orden público interior y la paz exterior; el debido respeto a la Instituciones y a las personas en la crítica de la acción política y administrativa; la independencia de los Tribunales, y la salvaguardia de la intimidad y del honor personal y familiar ${ }^{40}$.

La ambigüedad de este artículo fue fuente de múltiples arbitrariedades y la causa de la constante inseguridad de los editores y periodistas. En el artículo 3, se abolía formalmente la censura previa en las publicaciones, en un intento por alinearse con la tradición jurídica liberal, en la cual es el poder judicial quien condena los hechos delictivos $^{41}$. La desaparición de la censura previa trae como consecuencia el reforzamiento del aparato punitivo y el control sobre el proceso de producción. La censura previa fue sustituida por la consulta voluntaria y el depósito de los ejemplares, que seguirán pasando por un mecanismo arbitrario de censura idéntico al anterior ${ }^{42}$.

La Ley de 1966 trató de armonizar la «libertad responsable». Sin embargo, no consiguió resolver la contradicción por la cual se originó, la necesidad de libertad de expresión quedaba condicionada a los principios fundamentales del Régimen ${ }^{43}$.

37. Prólogo de la Ley 14/1966, de 18 de marzo, de Prensa e Imprenta

38. «El derecho a la libertad de expresión de las ideas reconocido a los españoles en el artículo doce de su Fuero se ejercitará cuando aquéllas se difundan a través de impresos, conforme a lo dispuesto en dicho Fuero y en la presente Ley", Artículo 1, Ley 14/1966, de 18 de marzo, de Prensa e Imprenta.

39. BOE, 18 de julio de $1945, n^{\circ} .199$, p. 358.

40. Artículo 2, Ley 14/1966, de 18 de marzo, de Prensa e Imprenta.

41. Gubern, Román: La censura. Función política..., p. 185; MenCHERO DE Los Ríos, Carmen: La modernización de la censura..., p. 69, sin embargo, la administración mantendrá en su poder la iniciación de los expedientes censorios que pasarán a manos del aparato judicial.

42. Artículo 4, Ley 14/1966, de 18 de marzo, de Prensa e Imprenta.

43. Cisquella, Georgina; ERviti, José Luis y Sorolla, José A.: La represión cultural en el franquismo..., p. 27. 
El proyecto continuista iniciado a mitad de la década de los sesenta prosiguió con la ordenación de la estructura institucional materializada en la Ley Orgánica del Estado de $1967^{44}$. Estos avances se vieron truncados por la instauración del estado de excepción en 1969 mediante decreto, que sacó a la luz el fracaso de la estrategia económica y la crisis política que estaba atravesando el franquismo. El estado de excepción fue utilizado por parte de las posiciones más reaccionarias del franquismo para recuperar la hegemonía y recomponer la ideología del Régimen ${ }^{45}$.

El periodo acotado entre los años 1969 y 1975 es la culminación de la acelerada descomposición política del franquismo. En 1969, Carrero Blanco destituyó a Fraga Iribarne y apostó por los tecnócratas, nombrando a Alfredo Sánchez Bella nuevo ministro de Información y Turismo. En 1973, sucedió un nuevo cambio de gobierno, en el cual Fernando Liñán y Zofio, miembro del Opus Dei, asumió la cartera del Ministerio de Información y Turismo. Con el asesinato de Carrero Blanco en diciembre de 1973, se desencadena una crisis de expectativas, y Franco le encargó a Carlos Arias Navarro la formación de un nuevo gobierno y el inicio de una reforma política que garantizase la continuidad del sistema. Pío Cabanillas asumió el Ministerio de Información y Turismo, pero fue cesado a los pocos meses por Franco, que juzgó su gestión como excesivamente liberal.

La Ley de Prensa e Imprenta de 1966 resultó ser un instrumento útil para el control ideológico que buscaba el Régimen, sin embargo, la necesidad de una planificación técnica e industrial del sector se antojaba imprescindible para promocionar y expandir el sector del libro. Durante el ministerio de Pío Cabanillas, una de las tareas programáticas que se plantearon fue la elaboración de una ley de libro que regulara el sector, y que especialmente formalizase los derechos de los autores. No fue hasta el ministerio de León Herrera cuando se promulgó la Ley del Libro de 1975, que ofrecía un marco jurídico al autor, regulaba la situación del INLE y establecía beneficios de carácter fiscal ${ }^{46}$.

La Ley de Prensa e Imprenta fue un intento de legitimación democrática sin cambiar los ejes de la cultura política impuesta a partir del 18 de julio. Es una ley que, a pesar de su proyección aperturista, se encontraba dentro de los admisibles por el Régimen ${ }^{47}$. Fue una estrategia de imagen del franquismo que buscaba generar la percepción de tolerancia y apertura del Régimen, sin embargo, la realidad es que

44. Carrillo, Marc: El marco jurídico-político de la libertad de prensa..., p. 5.

45. Cisquella, Georgina; ERviti, José Luis y SOROLla, José A.: La represión cultural en el franquismo..., p. 78, se decretó por primera vez el estado de excepción en el conjunto de España.

46. Cisquella, Georgina; ERviti, José Luis y Sorolla, José A.: La represión cultural en el franquismo..., p. 145.

47. CARrillo, Marc: El marco jurídico-político de la libertad de prensa..., p. 5, analiza la imagen que se buscaba proyectar de la ley como aperturista y generadora de nuevas cuotas de libertad y permisividad. 
adaptó y afianzó los mecanismos de tutela editorial al objetivo de dar continuidad a la Dictadura. Según Martínez Martín, la ley de 1966 perseguía modernizar los mecanismos de control de la cultura impresa, adaptando la represión a las nuevas disidencias ${ }^{48}$. El aumento y diversificación de las publicaciones hacía muy difícil su control, por ello, Fraga se dirigió a la médula de la producción editorial: los editores y las empresas editoriales ${ }^{49}$.

\section{El REgistro DE EMPRESAS EDITORIALES: UN INSTRUMENTO DE LA CENSURA FRANQUISTA}

La Ley de Prensa e Imprenta de 1966 significó la institucionalización y normalización del control del Régimen sobre el sector editorial ${ }^{50}$. Con su política continuista de exclusión ideológica y social ${ }^{51}$, el franquismo persiguió todo aquello que representara la "Anti España» ${ }^{52}$, transformando el panorama cultural y literario y estableciendo una única verdad 53 .

Las implicaciones y consecuencias de la Ley de Prensa e Imprenta han sido ampliamente tratadas. La censura editorial ha sido trabajada en diferentes investigaciones que van desde los primeros trabajos de Antonio Beneyto ${ }^{54}$, Manuel Abellán ${ }^{55}$ y los periodistas Georgina Cisquella, José Luis Erviti y José A. Sorolla ${ }^{56}$, hasta las más canónicas y actualizadas, como la Historia de la Edición de España de Jesús Martínez

48. Martínez Martín, Jesús A.: «Editoriales conflictivas y disidentes en tiempos de Dictadura (19661975)", Arbor Ciencia. Pensamiento y Cultura, vol. 187, n. 747, 2011, pp. 127-141, p. 128, https://doi. org/10.3989/arbor.2011.747n1014, estudia los expedientes de las editoriales consideradas como conflictivas y su papel en la agudización de las contradicciones entre los avances sociales y las reformas del Régimen.

49. Martínez Martín, Jesús A.: Historia de la edición en España ..., p. 274.

50. Cisquella, Georgina; ERviti, José Luis y SOROlla, José A.: La represión cultural en el franquismo..., p. 65 .

51. Aróstegui SÁnchez, Julio: "Opresión y pseudo - juricidad: de nuevo sobre la naturaleza del franquismo", Bulletin d'bistoire contemporaine de l'Espagne, 24, 1996, pp. 31-46.

52. MarTínez Rus, Ana: La persecución del libro. Hogueras, infiernos y buenas lecturas (1936-1951). Gijón: Trea, 2014, p. 12 aborda la destrucción del patrimonio bibliográfico español mediante la quema de libros, la depuración de fondos del mercado editorial y librero, y el expurgo de las bibliotecas como formas que tuvo el Régimen de acabar con la "Anti-España».

53. Ruiz Bautista, Eduardo, Los señores del libro.., p. 441; Ambrosi, Paola: "Nota sobre la censura». En: Martín Cabrero, Francisco José (ed.): Las novelas de 1902: Sonata de otoño. Camino de perfección, Amor y pedagogía, La voluntad. Madrid: UNED, Biblioteca Nueva, 2003, pp. 253-270.

54. Beneyto, Antonio: Censura y política en los escritores españoles. Barcelona: Editorial Euros, 1975.

55. Abellán, Manuel L.: Censura y creación literaria en España (1939-1976). Barcelona: Editorial Península, 1980.

56. Cisquella, Georgina; ERviti, José Luis; Sorolla, José A.: La represión cultural en el franquismo. Diez años de censura de libros durante la Ley de Prensa (1966-1976). Barcelona: Anagrama, 2002. 
Martín $^{57}$ o las obras de Ana Martínez Rus ${ }^{58}$, Fernando Larraz ${ }^{59}$, Eduardo Ruiz Bautista ${ }^{60}$ o Francisco Rojas Claros $^{61}$. Por otro lado, hay diversos trabajos que han analizado el control y la censura en la prensa como consecuencia de la Ley de $1966^{62}$.

La censura durante el franquismo no fue homogénea ni en el espacio, ni en el tiempo. Fue una herramienta de control político-social y un procedimiento del ejercicio arbitrario del poder, que estableció los límites de la política del libro ${ }^{63}$. El libro fue identificado como un objeto relacionado con la «alta cultura» y la práctica de la lectura podía ser un acto negativo dependiendo de qué se leyera y quién lo leyera ${ }^{64}$.

El tratamiento arbitrario al que fue sometida la producción literaria española por los responsables de la censura estuvo condicionado por la época, situación sociopolítica, quién era el escritor o el editor, el tema de la obra, el ámbito de difusión, etc. ${ }^{65}$. Existían una serie de criterios fijos y otros variables. Los primeros se refieren a los relacionados con el respeto al sistema institucional franquista, sus principios ideológicos y sus leyes. Estos criterios se mantuvieron intactos durante todo el periodo ${ }^{66}$. Los segundos, estaban relacionados con la moral pública y católica, y quedaban bajo la arbitrariedad del censor ${ }^{67}$.

Con la ley de 1966 la censura pasa de ser un instrumento de contención a ser una herramienta de transformación y represalia según las afinidades políticas de los

57. Martínez Martín, Jesús A.: Historia de la edición en España 1939-1975. Madrid: Marcial Pons Historia, 2015.

58. MarTínez Rus, Ana: La persecución del libro. Hogueras, infiernos y buenas lecturas (1936-1951). Op. cit.

59. LaRraz, Fernando: Letricidio español. Censura y novela durante el franquismo. Gijón: Trea, 2014.

60. Ruiz BAUTISTA, Eduardo: Los señores del libro: propagandistas, censores y bibliotecarios en el primer franquismo. Gijón: Trea, 2005.

61. Rojas Claros, Francisco: Dirigismo cultural y disidencia editorial en España (1962-1973). Alicante: Universidad de Alicante, 2013.

62. Cabe destacar los trabajos de Terrón Montero, Javier: La prensa en España durante el Régimen de Franco. Un intento de análisis político. Centro de Investigaciones Sociológicas, 1981; Barrera, Carlos: Periodismo y franquismo. De la censura a la apertura. Barcelona: Ediciones Internacionales Universitarias, 1995; Sinova, Justino: La censura de prensa durante el franquismo. Barcelona: Random House Mondadori, 2006.

63. Martínez Martín, Jesús A.: Historia de la edición en España..., p. 28.

64. Martínez Rus, Ana: La persecución del libro..., p. 69; Abellán, Manuel L.: "Fenómeno censorio y represión literaria", Diálogos Hispánicos de Ámsterdam, 5, 1987, pp. 5-25, p. 10, http://www.represura.es/ represura_2_enero_2007_articulo1.html

65. ABELlán, Manuel L: "Censura y autocensura en la producción literaria española" Nuevo Hispanismo, 1, 1982, pp. 169-180, pp. 170-172, http://www.represura.es/represura_4_octubre_2007_articulo6.html

66. Abellán, Manuel L: Censura y autocensura..., pp. 169-180 presenta un estudio cualitativo de los expedientes de censura basado en los archivos del Ministerio de Información y Turismo.

67. Abellán, Manuel L.: Censura y creación literaria en España (1939-1976). Barcelona: Península, 1980, p. 88.

(C) Ediciones Universidad de Salamanca / CC BY-NC-ND

Stud. hist., H. ${ }^{a}$ cont. 38, 2020, pp. 297-326 
escritores y editores, centrándose en el productor del contenido ${ }^{68}$. El discurso de Fraga de presentación de la ley en el Pleno de las Cortes insistió en evitar confundir la libertad de expresión con la libertad de prensa e imprenta. La primera era un derecho individual e inalienable, mientras que la segunda se referiría a los usos limitados que podía hacerse de un medio de difusión ${ }^{69}$. Además, la Ley de Prensa e Imprenta delegaba sobre la Administración la posibilidad de sancionar independientemente del desarrollo que el expediente tuviera posteriormente en el sistema judicial ${ }^{70}$, por lo que la mayoría de escritores y editores recurrieron a la "consulta voluntaria» por miedo a ser víctimas de la arbitrariedad ${ }^{71}$.

Se establecieron dos mecanismos de censura, los preventivos y los de castigo $^{72}$. La consulta voluntaria previa, el depósito de seis ejemplares de la obra en las dependencias del Ministerio de Información y Turismo y el Registro de Empresas Editoriales formaban parte del primer grupo ${ }^{73}$. Los dos primeros podían acabar con las obras siendo rechazadas o secuestradas; la inscripción en el Registro de Empresas Editoriales, sin embargo, era obligatoria para la práctica editorial y estaba condicionada por el envío de numerosa documentación que buscaba controlar la gestión y la línea de la editorial, así como la actividad de sus directores. El catedrático de la Universidad Complutense Jesús Martínez Martín tuvo la oportunidad, junto a su equipo de investigación, de consultar los fondos del Registro de Empresas Editoriales cuando todavía se encontraban alojados en el Archivo del Instituto Nacional del Libro Español ${ }^{74}$.

El Registro de Empresas editoriales ponía el foco de control sobre los agentes de producción, actuaba como mecanismo de supervisión obligando a los editores a superar los trámites de inscripción e impidiendo el normal funcionamiento de la editorial hasta que no consiguiera el número ${ }^{75}$. Diseñado como instrumento de control y mecanismo de intervención en el mundo editorial ${ }^{76}$, el Registro de Empresas Editoriales actuaba antes de que se cometiera la infracción en la producción o distribución de la obra ${ }^{77}$.

68. Abellán, Manuel L.: Fenómeno censorio y represión literaria ..., pp. 17-18.

69. ABellán, Manuel L: Censura y creación literaria..., p. 118.

70. "De la responsabilidad y de las sanciones", Capítulo X, Ley 14/1966, de 18 de marzo, de Prensa e Imprenta; Abellán, Manuel L: Censura y creación literaria..., p. 118.

71. ABELLÁN, Manuel L: Censura y creación literaria..., p. 119.

72. Cisquella, Georgina; ERviti, José Luis y Sorolla, José A.: La represión cultural en el franquismo..., p. 65.

73. Martínez Martín, Jesús A.: Editoriales conflictivas y disidentes en tiempos de Dictadura..., p. 128.

74. Proyecto "La política del libro y la industria editorial en España (1966-1986)», HAR2011 - 29343 , Ministerio de Educación, Cultura y Deporte, Investigador Principal: Jesús Antonio Martínez Martín.

75. Menchero de los Ríos, Carmen: La modernización de la censura..., p. 72.

76. MuÑOz Soro, Javier: Vigilar y censurar..., p. 115.

77. Cisquella, Georgina; ERviti, José Luis y Sorolla, José A.: La represión cultural en el franquismo..., p. 65 . 
El desarrollo jurídico de la Ley de Prensa e Imprenta dio lugar al Decreto 748/1966, de 31 de marzo, relativo al Registro de Empresas Editoriales cuyo objetivo era «dictar las normas reglamentarias que han de regular la mencionada inscripción y el funcionamiento del Registro de Empresas Editoriales de acuerdo con los preceptos de dicha Ley» ${ }^{78}$. Según la Ley de 1966 y el Decreto referente al Registro de Empresas Editoriales, una empresa editorial era

la constituida por personas naturales o jurídicas con nacionalidad española y residencia en España, que se encuentren en pleno ejercicio de sus derechos civiles y políticos y cuya actividad tenga por objeto la realización por cuenta propia de las publicaciones unitarias, libros, folletos, hojas sueltas, carteles y otros impresos análogos, siempre que se cumplan los requisitos que la Ley y el presente decreto establecen ${ }^{79}$.

La inscripción en el Registro de Empresas Editoriales quedaría plasmada en un «registro público» custodiado por el Ministerio de Información y Turismo y la Dirección General de Información ${ }^{80}$. Pese a la obligatoriedad del número de registro, éste podía ser retirado por el Ministerio cuando los libros producidos por la editorial no fueran de su agrado, alegando el incumplimiento del plan editorial ${ }^{81}$. Bajo esta amenaza, las editoriales vieron limitada constantemente su capacidad de producción, publicación y distribución de obras. Durante el período hasta conseguir el número de inscripción, pasar por la censura previa era obligatorio, por lo que, en ocasiones, el Ministerio de Información y Turismo prolongó este periodo para asegurarse el control sobre el contenido de los libros.

La documentación necesaria para conseguir la inscripción se debía entregar mediante instancia:

Artículo $3^{\circ}$ : El expediente de inscripción se iniciará a solicitud de la Empresa interesada, mediante instancia dirigida el Ministerio de Información y Turismo [...]

Artículo $4^{\circ}$ : Cuando la Empresa esté constituida por una persona natural, en la instancia se hará constar nombre, edad, nacionalidad y domicilio del titular. Dicha instancia irá acompañada de los siguientes documentos:

a) Declaración jurada de que el solicitante titular de la Empresa se halla en el pleno ejercicio de sus derechos civiles y políticos.

78. Decreto 748/1966, de 31 de marzo, relativo al Registro de Empresas Editoriales, BOE, 31 de marzo de 1966, n. $^{\circ} 80$, p. 3962.

79. Artículo 10 y 52, Ley 14/1966, de 18 de marzo, de Prensa e Imprenta; Artículo 1, Decreto 748/1966, de 31 de marzo, relativo al Registro de Empresas Editoriales, BOE, 31 de marzo de 1966, n. ${ }^{\circ}$ 80, p. 3962.

80. Artículo 51, Ley 14/1966, de 18 de marzo, de Prensa e Imprenta; Artículo 2, Decreto 748/1966, de 31 de marzo, relativo al Registro de Empresas Editoriales, BOE, 31 de marzo de 1966, n. ${ }^{\circ}$ 80, p. 3962.

81. Artículo 29 y 30, Ley 14/1966, de 18 de marzo, de Prensa e Imprenta; Cisquella, Georgina; ERviTI, José Luis y Sorolla, José A.: La represión cultural en el franquismo..., p. 65. 
b) Declaración comprensiva de los nombres, apellidos, nacionalidad y domicilio del fundador o fundadores de la Empresa y, en su caso, de la persona o personas a quien se encomiende la administración o gestión.

c) Reglamento de la Empresa editorial, si lo hubiera.

d) Descripción del patrimonio de la Empresa.

e) Exposición de las líneas generales del plan editorial y financiero que se pretende desarrollar y de los medios con que se cuenta para su realización.

Artículo $5^{\circ}$ : Cuando se trate de personas jurídicas, en la instancia en que se solicite la inscripción habrán de figurar los siguientes datos:

1. Nombre, edad, profesión, naturaleza y domicilio de la persona que firma la solicitud, así como de la escritura pública que acredite el poder o representación que faculta para solicitar la inscripción.

2. Nombre y razón social, nacionalidad y domicilio de la persona jurídica titular de la Empresa editorial.

A la instancia mencionada se acompañarán los documentos siguientes:

a) Copia autorizada de los Estatutos sociales y del Reglamento, si lo hubiere. Cuando la forma jurídica adoptada sea la de Sociedad, se presentará, además, copia autorizada de la escritura pública de constitución, con certificación del correspondiente asiento en el Registro Mercantil.

b) Certificación acreditativa de los nombres, apellidos, nacionalidad y domicilio del fundador o fundadores, si continúan participando en la Empresa editorial, y de las personas a las que se encomienda la gestión y administración, acreditando que se encuentran en pleno ejercicio de sus derechos civiles y políticos. Cuando la forma jurídica adoptada sea la de Sociedad, se presentará copia autorizada de los acuerdos sociales relativos al nombramiento de administradores y Gestores, y composición de los órganos de administración y Gestión.

c) Certificación acreditativa de los elementos que constituyen el patrimonio de la Empresa y, en su caso, del capital social suscrito y del desembolsado, en la que se contenga:

1. Relación de los accionistas [...]

2. Copia autorizada de las escrituras de constitución de las Sociedades que sean titulares de acciones de la Empresa editorial [...]

d) Exposición de las líneas generales del plan financiero y medios para su realización ${ }^{82}$

La disposición transitoria primera de la Ley de Prensa e Imprenta especificaba que la inscripción en el Registro de Empresas Editoriales debía efectuarse en el plazo de un año después de la entrada en vigor de la Ley ${ }^{83}$. Los trámites exigidos iban más allá del control administrativo, como demuestra la necesidad de entregar el plan editorial o las declaraciones de los fundadores, accionistas y demás implicados en la editorial de encontrarse en el pleno ejercicio de sus derechos civiles y políticos. Una

82. Artículos 3, 4 y 5, Decreto 748/1966, de 31 de marzo, relativo al Registro de Empresas Editoriales, BOE, 31 de marzo de 1966, n. ${ }^{\circ} 80$, p. 3963.

83. Disposición transitoria primera, Ley 14/1966, de 18 de marzo, de Prensa e Imprenta. 
vez presentados todos los requisitos, los promotores, fundadores y accionistas de la editorial podían ser objeto de un informe policial, que se centraba no solamente en sus implicaciones políticas, sino también en actividades de su vida privada ${ }^{84}$. Esto quedaba amparado por el artículo 53 de la Ley de Prensa e Imprenta y por el artículo 7 del Decreto 748/1966 «recibida la solicitud de inscripción con los documentos que la acompañen de acuerdo con los artículos precedentes, la dirección General de Información tramitará el expediente practicando para ello las comprobaciones que estime oportunas». Si el historial de los fundadores o accionistas era sospechoso, entonces el contenido y la estructura del plan editorial pasaba a ser un condicionante para la aprobación de la inscripción ${ }^{85}$.

La retirada del número de inscripción significaba la prohibición de la actividad editorial y en la práctica era el fin de la editorial. Bastaba con que el Ministerio de Información y Turismo considerase que había habido una modificación sustancial de los datos aportados durante los trámites para la inscripción para retirar el número de inscripción a la editorial. Las empresas editoriales inscritas debían comunicar semestralmente cualquier cambio que se produjese, o podrían ser sancionadas ${ }^{86}$.

En paralelo a las gestiones oficiales se abrieron una serie de cauces como las llamadas telefónicas, las reuniones con el Ministerio, los contactos personales, que sostuvieron todo un entramado de redes extraoficiales que se fue consolidando hasta generar una negociación paralela con el fin de conseguir el número de inscripción ${ }^{87}$.

Este proceso de inscripción obligatorio derivó en una falta de libertad de creación en las industrias culturales. La retirada del número de inscripción se utilizó en bastantes ocasiones para cortar de raíz una crítica ideológica contra el Régimen ${ }^{88}$. El Registro de Empresas Editoriales es una prueba más del falseamiento de los propósitos iniciales de la Ley de Prensa e Imprenta, donde los expedientes quedaban en manos de la arbitrariedad de un funcionario.

84. En este contexto, como explica MENCHERO DE LOS Ríos, Carmen: La modernización de la censura..., p. 72, muchas editoriales cambiaron sus datos a lo largo de los trámites, transformando los nombres de los directores, el plan editorial o la procedencia de los accionistas, aspirando con los nuevos cambios a acceder con mayor facilidad al número de inscripción.

85. MenChero de los Ríos, Carmen: La modernización de la censura..., p. 73.

86. Artículo 9, Decreto 748/1966, de 31 de marzo, relativo al Registro de Empresas Editoriales, BOE, 31 de marzo de 1966, n. $^{\circ} 80$, p. 3962

87. Menchero de los Ríos, Carmen: La modernización de la censura..., p. 72.

88. Cisquella, Georgina; ERviti, José Luis y Sorolla, José A.: La represión cultural en el franquismo..., p. 66. 


\section{El FONDO documental: Del Instituto Nacional del Libro Español al ArChivo} GENERAL DE LA ADMINISTRACIÓN

En 1985, mediante la Ley de Presupuestos Generales, el Estado establece la supresión del Instituto Nacional del Libro Español ${ }^{89}$. Este organismo fue disuelto mediante Real Decreto en 1986 y sus competencias pasaron a formar parte de la Dirección General del Libro y Bibliotecas, que se hizo cargo de su archivo ${ }^{90}$. La reapertura de los archivos del INLE no fue posible hasta el año 2005. A través de la Biblioteca del Libro y la Lectura, que forma parte del Centro de Documentación del Libro, la Lectura y las Letras, se clasificó el archivo documental perteneciente al INLE.

No obstante, los fondos dedicados a los «Registros de Empresas (1962-1993)» fueron traspasados al Archivo General de la Administración y quedaron bajo su custodia:

REGISTRO DE EMPRESAS (1962-1993):

8.1 Expedientes de Registro de Empresas Editoriales.

8.2 Expedientes de Registro de Empresas Importadoras de Publicaciones Extranjeras.

8.3 Expedientes de Registro de Librerías.

8.4 Expedientes de Registro de Distribuidores.

8.5 Libros de Registro de Empresas Editoriales.

8.6 Libros de Registro de Empresas Importadoras de Publicaciones Extranjeras ${ }^{91}$.

Los registros mantuvieron la clasificación inicial otorgada por la Biblioteca del Libro y la Lectura. Nuestra investigación presta especial atención a los fondos denominados "Ficheros de registro de empresas editoriales", "Relaciones de empresas editoriales», y los expedientes de las empresas editoriales inscritas en el Registro.

\subsection{Los ficheros de registro de empresas editoriales}

Este fondo se compone de varios ficheros que tienen como objetivo ordenar las empresas inscritas en el Registro de Empresas Editoriales:

- Fichas de las empresas inscritas en el REE en las que consta: nombre de la empresa, número de inscripción, capital social, localidad, nombre del solicitante de la inscripción, nombres de los fundadores, nombres y cargos de los integrantes del Consejo de Administración, nombres de los accionistas y número de acciones que poseen ${ }^{92}$.

89. Ley 50/1984, de 30 de diciembre, de Presupuestos Generales del Estado para 1985, artículo 85. «BOE» núm. 313, de 31 de diciembre de 1984, páginas 37557 a 37586.

90. Real Decreto 875/1986, de 21 de marzo, por el que se suprime el Organismo autónomo Instituto Nacional del Libro Español, artículos 1 y 2. «BOE» núm. 108, de 6 de mayo de 1986, páginas 15943 a 15943.

91. Ibidem.

92. AGA, Cultura, 62/07185; AGA, Cultura, Fichero de Registro de Empresas Editoriales (A - E), 62/07186; Fichero de Registro de Empresas Editoriales (E - M), 62/07187; Fichero de Registro de Empresas Editoriales (N - Z), 62/07188. 
- Fichas de los cargos y responsabilidades de las empresas ${ }^{93}$.

- Fichas de las empresas ordenadas según el nombre del propietario ${ }^{94}$

- Fichas de las empresas cuya inscripción se encuentra en trámite ${ }^{95}$.

- Fichas de las empresas solicitantes entre los años 1982 y $1988^{96}$.

- Fichas de las empresas solicitantes entre los años 1989 y $1990^{97}$.

- Fichas de los propietarios de las empresas ${ }^{98}$.

Estos ficheros fueron realizados por los funcionarios del Ministerio de Información y Turismo con el objetivo de ordenar la información proporcionada por los expedientes del Registro de Empresas Editoriales. Esta documentación resulta especialmente útil a la hora de estudiar las relaciones que se mantuvieron entre las diferentes empresas editoriales y las personas que formaban parte de las mismas. Asimismo, nos permite seguir el hilo de la historia de las editoriales, pues cuando la información de alguna de ellas cambiaba se añadía una ficha a modo de anexo con los nuevos datos. Además, en las fichas relacionadas con las empresas que se encuentran cursando el trámite de inscripción viene especificado el motivo de desestimación de la solicitud o la fecha de caducidad de esta, siendo muchas de ellas editoriales que han publicado obras sin estar inscritas en el Registro de Empresas Editoriales.

\subsection{Las relaciones de las empresas editoriales}

Esta documentación consiste en listas que relacionan diferentes características de las editoriales ${ }^{99}$ :

- Relación de empresas inscritas en el Registro ordenadas según la provincia a la que pertenecen.

- Relación de empresas del Ministerio de Información y Turismo y de la Secretaría General del Movimiento.

- Relación de empresas con capital extranjero o de españoles residentes en el extranjero inscritas en el Registro.

- Relación de empresas inscritas transitoriamente en el Registro.

- Relación de empresas a las que se ha remitido notificación y no han sido localizadas en el domicilio que figura en el expediente.

93. AGA, Cultura, 62/07185.

94. AGA, Cultura, 62/07189.

95. AGA, Cultura, 62/07190

96. AGA, Cultura, 62/07191.

97. AGA, Cultura, 62/07192.

98. AGA, Cultura, Fichero de Registro de Empresas Editoriales, por propietario (A - E), 62/07192; Fichero de Registro de Empresas Editoriales, por propietario (E - Z), 62/07192.

99. AGA, Cultura, 62/06660; AGA, Cultura, 62/06661. 
- Relación de organismos oficiales inscritos en el Registro.

- Relación de partidos políticos inscritos en el Registro.

- Relación de empresas con capital mexicano inscritas en el Registro.

- Relación de empresas conflictivas.

- Relación de empresas especializadas en formación profesional y maestría industrial.

- Relación de empresas relacionadas con la cultura.

- Relación de empresas que editan publicaciones infantiles o juveniles.

- Relación de empresas importadoras de publicaciones extranjeras.

Los fondos citados permiten conocer la composición del capital que sustentaba la editorial, los motivos de las bajas de las inscripciones del Registro de Empresas Editoriales, y el motivo por el que el Régimen consideraba conflictivas ciertas editoriales. Esto último es especialmente relevante si tenemos en cuenta que muchas de las editoriales que aparecen en el listado vieron paralizado o denegado el proceso de su inscripción en el Registro.

\section{Los EXPEDIENTES DEL Registro DE EMPRESAs Editoriales: LA Distribuidora ENLACE}

El Registro de Empresas Editoriales terminó siendo una herramienta de control de las editoriales. El proceso burocrático de inscripción requería de gran astucia por parte de los editores. Es el caso de Ediciones de Cultura Popular, en 1966, y de la editorial Akal, en 1973, ambas conocidas por la publicación de libros de carácter social, que se vieron forzadas a incluir en sus planes editoriales libros de cocina, jardinería o conducción de automóviles, con el objetivo de facilitarse la obtención del número de registro, aunque esos libros nunca llegaron a publicarse. Otras editoriales vieron truncado su camino hacia el número de inscripción cuando el Ministerio de Información y Turismo detectó actividades sospechosas que afectaban a sus fundadores o a los participantes de la editorial. Fue el caso de las editoriales Nova Terra, Seix Barral, Seminarios y Ediciones, S. A. (SESA) o Siglo XXI que, a pesar de haber conseguido el número, el Ministerio les impuso la obligatoriedad de someter todos sus libros a "censura previa»100. Por el contrario, el consejo editorial de la Editorial Artiach tomó la decisión de no acatar la censura previa y la editorial acabó desapareciendo ${ }^{101}$.

100. Cisquella, Georgina; ERviti, José Luis y Sorolla, José A.: La represión cultural en el franquismo..., p. 68.

101. Ruiz Bautista, Eduardo, Los señores del libro..., p. 121. 
Tal y como aborda Jesús Martínez Martín, una vez concedido el número de registro, el Ministerio cuestionó en varias ocasiones la inscripción de diversas editoriales por diferentes motivos. Fue el caso de la editorial Zero Zix que, pese a ser conocida por su disidencia, consiguió mantener su número de inscripción gracias a las buenas referencias de sus fundadores ${ }^{102}$. En muchas ocasiones, no había una negativa explícita a la concesión del número de registro, pero los funcionarios del Ministerio dilataban el proceso iniciando peticiones burocráticas a las editoriales, que se vieron inmersas en un proceso de años, como Edicions 62, que tardó cinco años en conseguir su número de inscripción.

Uno de los procesos más importantes es el de Ciencia Nueva, una editorial fundada en 1958, de pensamiento marxista, que solicitó la inscripción en 1967 y funcionó sin número de registro hasta 1969, cuando fue cancelada su inscripción y declarado el "cierre administrativo» junto con Ediciones Halcón, Ricardo Aguilera y Equipo Editorial de San Sebastián ${ }^{103}$.

Al calor del boom editorial catalán, en Barcelona durante el año 1970 fue creada la Distribuidora Enlace, integrada por las editoriales catalanas Barral Editores, Edicions 62, Lumen, Tusquets, Anagrama, Laia, Fontanella, y la madrileña Cuadernos para el Diálogo, y distribuidora de las obras de la Gaya Ciencia. Estas editoriales formaban parte de una nueva generación de editores, perteneciente a la burguesía intelectual catalana, que asumió una posición de ruptura democrática con el Régimen franquista, con posturas abiertamente europeístas y con notables influencias de los movimientos del 68. Por esta razón, y porque sus expedientes contienen características interesantes para la investigación, hemos seleccionado estas editoriales para su estudio.

En general, los expedientes de las editoriales están compuestos por la misma documentación, que guiaba el trámite que debía realizar la editorial para conseguir el número de registro. Abre el expediente la instancia solicitando al Ministerio de Información y Turismo la inscripción en el Registro de Empresas Editoriales de la editorial, le siguen los documentos consignados por la ley: la declaración jurada de los propietarios y participantes de la editorial de hallarse en el pleno ejercicio de sus derechos civiles y políticos, la declaración con los datos del fundador o fundadores, la declaración con los datos sobre la gerencia y administración de la empresa, el reglamento o la declaración de su no existencia, el plan editorial —contenía las colecciones, las obras fuera de colección, el público al que iban dirigido...-, el plan financiero y los medios para su realización, y la descripción del patrimonio detallando el capital social,

102. Martínez Martín, Jesús A.: Editoriales conflictivas y disidentes en tiempos de Dictadura ..., p. 129.

103. Rojas Claros, Francisco: "Una editorial para los nuevos tiempos: Ciencia Nueva (1965-1970)", Revista Historia del Presente, 5, 2005, pp. 103-120, p. 107. Disponible en: http://historiadelpresente.es/sites/ default/files/revista/articulos/5/505unaeditorialparalosnuevostiemposciencianueva.pdf; Menchero de los Ríos, Carmen: La modernización de la censura..., p. 67. Otros casos han sido tratados por Martínez MarTín, Jesús A.: Editoriales conflictivas y disidentes en tiempos de Dictadura... 
el capital inmovilizado y los bancos con los que se mantenía relación. Si las editoriales eran Sociedades Anónimas, debían entregar la escritura de constitución o la certificación de asiento en el Registro Mercantil. Tras haber entregado dichos documentos la editorial, aparece una carta remitida desde el Servicio de Orientación Bibliográfica del Ministerio comunicando la no procedencia de la inscripción en el Registro de Empresas Editoriales por estar incompleta la documentación. Son escasas las editoriales que consiguen la inscripción con la primera entrega de la documentación, y una muestra de la arbitrariedad de los funcionarios del Ministerio es que no siempre se solicitaba la misma documentación a las editoriales. Si todo continúa de manera positiva y la editorial entrega la documentación solicitada, a continuación, aparece la resolución de concesión de número de registro por parte del jefe del Registro de Empresas Editoriales, junto con el Decreto ratificando la decisión de la inscripción de la editorial en el Registro concedida por Ministro de Información y Turismo, y la comunicación a la editorial de la concesión.

El 2 de febrero de 1967, el Director General de la Editorial Lumen, Ramón Cavanillas, recibió una carta del Ministerio de Información y Turismo en la que se exigía a la editorial la inscripción en el Registro de Empresas Editoriales antes del 9 de abril de $1967^{104}$. Esta era la fecha indicada para la finalización del plazo de un año que había sido concedido a las editoriales desde la publicación de la Ley de Prensa e Imprenta hasta la formalización de su inscripción en el Registro de Empresas Editoriales ${ }^{105}$. El propio Cavanillas, ya había mostrado su disposición a iniciar los trámites de la inscripción pero, como refleja en su respuesta al Ministerio, la Delegación de Barcelona no contaba con la documentación necesaria para su envío. El 6 de febrero de 1967 el Ministerio les remitió la documentación necesaria y, un mes más tarde, la editorial depositó en registro la documentación para la inscripción en el Registro de Empresas Editoriales ${ }^{106}$. Este particular comienzo del expediente de la editorial Lumen, contrasta con el resto de los expedientes de editoriales de Enlace, que se inician con la «Instancia de inscripción en el Registro de Empresas Editoriales». En el caso de las editoriales que se constituyeron como Sociedades Anónimas, esta instancia de solicitud aparece en dos ocasiones, como es el caso de la editorial Lumen ${ }^{107}$, La Gaya Ciencia ${ }^{108}$ y Tusquets Editores ${ }^{109}$.

104. AGA, Cultura, 62/06391, 21/5, "Carta del Director General de Lumen al Registro de Empresas Editoriales", 2 de febrero de 1967, Barcelona.

105. Disposición transitoria Primera de la Ley 14/1966, de 18 de marzo, de Prensa e Imprenta.

106. AGA, Cultura, 62/06391, 21/5, «Instancia de inscripción en el Registro de Empresas Editoriales de Editorial Lumen", 12 de marzo de 1967, Barcelona.

107. Se constituyó como Sociedad Anónima el 5 de julio de 1980. AGA, Cultura, 62/06391, 21/5, "Escritura de Constitución ante Notario de Editorial Lumen, S.A.", 5 de julio de 1980, Barcelona.

108. Se constituyó como Sociedad Anónima el 28 de junio de 1973. AGA, Cultura, 62/06485, 115/7, "Escritura de Constitución ante Notario de La Gaya Ciencia, S.A.», 28 de junio de 1973, Barcelona.

109. Se constituyó como Sociedad Anónima el 22 de abril de 1977. AGA, Cultura, 62/06448, 78/4, "Escritura de Constitución ante Notario de Tusquets Editores, S.A.», 22 de abril de 1977, Barcelona. 
Junto con la instancia, los editores formalizaron la documentación necesaria para conseguir el número de registro. Entre los distintos expedientes, destaca el plan editorial entregado por Óscar Tusquets y Beatriz de Moura para inscribir Tusquets Editores. Anteriormente, nos hemos referido a la importancia que otorgaba el Ministerio al plan editorial para discernir si concedía la inscripción a una editorial. Por ello, cabe detenerse en la "Propuesta para una colección de textos y autores libertarios", presentada por Tusquets al Ministerio como parte de su plan editorial, donde se especifican los títulos y tipos de publicación:

[...] Textos de los clásicos del movimiento libertario: Bakunin, Kropotkin, Malatesta, Proudhon, Fourier, etc.

- Textos de autores más recientes, en particular norteamericanos, franceses, ingleses y rusos.

- Historia de los distintos movimientos libertarios en diferentes países: España, Rusia, América (del Norte y Latinoamérica), Francia, Italia, Alemania, Rusia y China.

Documentos y manifiestos (en algunos casos por países o grupos de países, en otros por tipos distintos de movimientos, en otros por simple orden cronológico) [...] $]^{110}$.

Pese a lo controvertido de esta propuesta, dado el contexto en el que se desarrolló, el 14 de junio de 1969, Tusquets recibió el número de inscripción 796/69 en el Registro de Empresas Editoriales, tan sólo seis meses después de su solicitud ${ }^{111}$. Beatriz de Moura ha dado cuenta en diversas ocasiones de cómo tuvo que negociar mano a mano con los censores del Ministerio la colección Acracia, dedicada al pensamiento libertario ${ }^{112}$.

Una vez era entregada la documentación por parte de las editoriales, los expedientes nos muestran que se iniciaba un proceso de investigación, por parte del Ministerio y los funcionarios del Registro, a los promotores y participantes de las editoriales. En este proceso se ven afectadas editoriales como La Gaya Ciencia, Edicions 62 y Laia. El 30 de septiembre de 1971, la Sección del Registro de Empresas, del Servicio de Ordenación Editorial, de la Dirección de Cultura Popular y Espectáculos, del Ministerio de Información y Turismo, solicitaba al Delegado Provincial de Información y Turismo de Barcelona, un informe y antecedentes político-sociales de Rosa Regás ${ }^{113}$. Dicho informe elaborado por la Jefatura Superior de Policía de Barcelona fue remitido el

110. AGA, Cultura, 62/06448, 78/4, "Propuesta para una colección de textos y autores libertarios», 18 de enero de 1969, Barcelona.

111. AGA, Cultura, 62/06448, 78/4, «Resolución y decreto de inscripción de Tusquets Editores en el Registro de Empresas Editoriales", 14 de junio de 1969, Madrid.

112. VV. AA: Conversaciones con editores. En primera persona. Madrid: Siruela, 2007, pp. 187-188.

113. AGA, Cultura, 62/06485, 115/7, «Petición al Sr. Delegado Provincial de Información y Turismo de Barcelona de un informe y de los antecedentes político - sociales de Rosa Regás Pagés», 30 de septiembre de 1971, Madrid. 
23 de noviembre del mismo año, especificando una serie de actividades sospechosas y constitutivas de delito dentro de la legislación franquista ${ }^{114}$. El contenido del informe hizo que el Ministerio optase por ralentizar el proceso de inscripción: pasaron tres años desde que Rosa Regás entregó la instancia de solicitud el 14 de septiembre de 1971, hasta que consiguió el número de registro el 25 de junio de $1974^{115}$. Durante este periodo, en 1973, la Gaya Ciencia se constituyó como Sociedad Anónima, siendo sus principales accionistas: Oriol Regás Pagés, Rosa Regás Pagés y Oriol Bohigas Guardiola $^{116}$. Las investigaciones de los funcionarios del Registro se reactivaron a comienzos de 1974, cuando solicitaron un informe y antecedentes político-sociales de los tres accionistas ${ }^{117}$. Dicho informe fue de nuevo remitido por la Brigada Social de la Jefatura Superior de Policía de Barcelona, dando cuenta de los antecedentes de los tres integrantes de la editorial ${ }^{118}$.

En el caso de Edicions 62, las alarmas saltaron en el Ministerio por una noticia publicada por el noticiario francés Le Monde el 15 de septiembre de 1964. Tres años después, en junio de 1967, cuando la editorial inició el proceso de inscripción en el Registro, la Inspección del Servicio de Orientación Bibliográfica recibió de los servicios informativos de la Dirección General de Prensa los antecedentes de la editorial, entre los que consta dicha noticia:

"Servicio de Orientación Bibliográfica. Inspección.

Antecedentes según servicios informativos de la Dirección General de Prensa.

Prensa francesa:

El director alemán de «Ediciones 62»

Editor de libros en lengua catalana

Ha sido expulsado de España.

«Le Monde», centro izquierda, París, 15.09.1964.

Max Emmanuel Cahner, gerente de "Ediciones 62», ha sido expulsado de España. Tenía la nacionalidad alemana, aunque residía en España desde su infancia. Su expulsión ha causado gran sorpresa e inquietud en los círculos literarios catalanes, donde es muy conocido como editor de obras en catalán. Se ignoran todavía las causas que han determinado la expulsión. Se supone que se trata de una medida de represalia adoptada

114. AGA, Cultura, 62/6485, 115/7, «Informe de la Jefatura Superior de Policía de Barcelona sobre Rosa Regás Pagés», 23 de noviembre de 1971, Barcelona.

115. AGA, Cultura, 62/6485, 115/7, "Resolución y decreto de inscripción de La Gaya Ciencia, S. A. en el Registro de Empresas Editoriales», 14 de junio de 1969, Madrid.

116. AGA, Cultura, 62/06485, 115/7, "Escritura de Constitución ante Notario de La Gaya Ciencia, S.A.», 28 de junio de 1973, Barcelona.

117. AGA, Cultura, 62/06485, 115/7, «Petición al Sr. Delegado Provincial de Información y Turismo de Barcelona de un informe y de los antecedentes político-sociales de Oriol Regás Pagés, Rosa Regás Pagés y Oriol Bohigas Guardiola», 16 de febrero de 1974, Madrid.

118. AGA, Cultura, 62/6485, 115/7, «Informe de la Jefatura Superior de Policía de Barcelona sobre Oriol Regás Pagés, Rosa Regás Pagés y Oriol Bohigas Guardiola», 23 de marzo de 1974, Barcelona. 
por algunos funcionarios subalternos que no aprueban la política de «liberalización" del Ministerio de Información. Estos dos últimos años, el Ministerio de Información ha dado grandes facilidades para la edición de obras en catalán. Este mismo Ministerio acaba de autorizar la publicación de un nuevo suplemento semanal en lengua catalana del nuevo periódico TELE EXPRESS, que aparecerá en Barcelona a partir del martes próximo ${ }^{119}$.

Edicions 62 esperó cinco años hasta conseguir el número de registro en 1972. En 1971, se reactivó el proceso de investigación y el Ministerio emitió un "Resumen de la actividad editorial de Edicions 62", donde hacía constar la relación de obras presentadas a censura previa y las obras que habían sido denegadas entre los años 1964 y $1969^{120}$. Meses después, el Ministerio plasmó sus investigaciones en una serie de documentos confidenciales que seguirían dilatando el proceso de inscripción de la editorial, entre los que constan:

- Listado de todos los accionistas de Ediciones 62.

- Informe sobre la Editorial 62:

- Datos de antecedentes de D. Max Emmanuel Cahner García, D. Agustín Durán y Sanpere, y D. Ramón Bastardas Porcel, responsables de la editorial.

- Resumen de la actividad editorial de los años 1964, 1965, 1966, 1967, 1968, 1970, 1971 y 1972, con indicación de las obras para las que se han denegado su edición y las de silencio administrativo.

- Listado de los antecedentes que constan sobre diferentes accionistas de la editorial.

- Por acta, de 03.11.1966, levantada tras visita de inspección a la editorial, habiendo encontrado fijación de carteles de propaganda sin haber cumplido los requisitos de previo depósito de ejemplares.

- Ayuda de editoriales a elementos comunistas. Por recomendación de José María Castellet, escritor filocomunista de reconocida actuación contraria al Régimen, ha sido colocado en la labor de traducción y composición de libros en las editoriales de Barcelona, Ediciones 62 y Seix Barral, el miembro del Comité Central del Partido Comunista de España, Miguel Núñez González, que salió de la cárcel en libertad provisional recientemente ${ }^{121}$.

Por último, la editorial Laia tardó tres años en conseguir el número de registro pese a las promesas realizadas por el Ministerio a los propietarios de la Editorial Estela. Con la llegada de la documentación al Registro, los funcionarios no hicieron ninguna excepción con el expediente de Laia, e inmediatamente solicitaron un informe y los

119. AGA, Cultura, 62/06468, 98/10, "Antecedentes de Ediciones 62 en la prensa", 2 de junio de 1967, Madrid.

120. AGA, Cultura, 62/06468, 98/10, "Resumen de la actividad editorial de Edicions 62», 1971, Madrid.

121. AGA, Cultura, 62/06468, 98/10, "Documentación interna del Registro de Empresas Editoriales, Edicions 62", 1972, Madrid. 
antecedentes político-sociales de los fundadores que, debido su participación en la Editorial Estela, dilató el proceso durante años, como en los casos anteriores ${ }^{122}$.

Con el objetivo de conseguir el número de inscripción, los editores hicieron valer su red de amistades e influencias para asegurarse que sus editoriales fueran inscritas en el Registro de Empresas Editoriales. Rosa Regás, tras tres años esperando el número de inscripción de la Gaya Ciencia, se dirigió a Ricardo de la Cierva, Director General de Cultura en 1974, pensando que éste escucharía sus ruegos y facilitaría la inscripción de su editorial:

Excelentísimo Señor,

Me permito molestar su atención para exponerle la situación de Editorial La Gaya Ciencia, S.A., de la que soy Director-Gerente.

Según consta en la fotocopia, adjunta del documento, el día 14 de septiembre de 1971 hice la inscripción en el Registro General de Editorial La Gaya Ciencia, empresa particular que figuraba a mi nombre. Entonces se me concedió permiso para editar, siempre que presentara todos los libros a consulta voluntaria, en espera de que se me otorgara el Número de Registro.

Cuando Editorial La Gaya Ciencia se convirtió en Sociedad Anónima hice los trámites pertinentes, volviendo a inscribir dicha Editorial en el Registro General como tal Sociedad. Incluyo también fotocopia de esta inscripción.

Durante estos tres años he solicitado en diversas ocasiones, información sobre la tardanza - y los motivos que el Ministerio puede tener- en solucionar y legalizar la situación de esta Empresa. Pero hasta la fecha no he tenido noticia alguna.

Esta Editorial publica libros de Arquitectura, una colección juvenil y una serie de obras de escritores contemporáneos. Tal como podrá ver en los folletos adjuntos, ninguno de los títulos ofrece el más mínimo peligro, y la orientación de la línea editorial no sale en ningún caso de los límites que otorga la ley de prensa.

A la vista de lo expuesto anteriormente y con la confianza que me otorga el interés tantas veces demostrado por Vd. en legalizar y clarificar situaciones parecidas a la que me ocupa, me permito rogarle se digne a considerar este caso, uno de los pocos no solucionados al cabo de casi tres años.

Gracia que espero recibir de su recto proceder, al mismo tiempo que le ruego reciba mi respetuoso saludo,

Rosa Regás ${ }^{123}$.

No podemos asegurar que debido a esta carta Rosa Regás consiguiera el ansiado número de inscripción, pero lo cierto es que, un mes después de la escritura de la carta,

122. AGA, Cultura, 62/06485. Documentación no accesible hasta 2012 en virtud de la aplicación de la Ley del Patrimonio Histórico Español 16/1985.

123. AGA, Cultura, 62/6485, 115/7, "Carta de Rosa Regás al Director General de Cultura, Ricardo de la Cierva", 8 de mayo de 1974, Barcelona. 
la Gaya Ciencia conseguía el número 1264/74 del Registro de Empresas Editoriales ${ }^{124}$, que fue consecuentemente agradecido por Rosa Regás a Ricardo de la Cierva:

Exmo. Señor,

Acabo de recibir la notificación del Ministerio por la que se otorga el número de Registro Editorial a La Gaya Ciencia, S.A.

Quiero que quede constancia de mi agradecimiento, al ser atendida la petición que le hice recientemente. Y al mismo tiempo felicitarle por su actuación en el reciente atentado a Distribuciones Enlace, que también distribuye los libros de La Gaya Ciencia, y que viene a corroborar la confianza que los Editores hemos depositado en el interés que Vs. ha demostrado siempre en todos nuestros problemas.

Esperando tener ocasiones de reiterarle mi agradecimiento personalmente en alguna ocasión, le ruego acepte el testimonio de mi admiración por su labor y de mis afectos sinceros,

Rosa Regás ${ }^{125}$.

José Maria Castellet, ya como Director Literario de Edicions 62, siguió la misma estrategia que la editora de la Gaya Ciencia, y en septiembre de 1972 se dirigió al Director General de Cultura Popular:

Mi querido amigo,

Me permito molestarte de nuevo a propósito de la conversación que mantuvimos en el mes de julio, en tu despacho, con nuestros consejeros Viladás y Vergés.

En el primer Consejo de Administración de la editorial celebrado después del verano, nuestro presidente, el notario de Barcelona, D. F. De P. Llach — hombre que, por profesión tiene la justa obsesión de la legalidad- insistió mucho en la necesidad de resolver esta cuestión de la falta de número de registro, que tanto nos perjudica, frente a terceros en nuestras cuestiones de ampliación de capital, por ejemplo, y frente a la misma administración por la imposibilidad de solicitar créditos u otros beneficios legales.

Creo, por otra parte, que habrás podido tratar el tema con el Sr. Sánchez Marín, que es la persona que en el Ministerio mejor conoce la trayectoria de Edicions 62 y cuya opinión, en este sentido, estoy seguro que es complemente justa.

Como ya te dijimos en el mes de julio, al insistir sobre este tema, no perseguimos más que la legalización de una situación que se ha alargado demasiado, puesto que por nuestra parte nos comprometemos a seguir presentando todos los textos que vayamos a publicar a consulta previa.

Con gracias anticipadas por tu interés y en espera de tus noticias, te saluda muy afectuosamente,

J.M. Castellet ${ }^{126}$.

124. AGA, Cultura, 62/6485, 115/ 7, «Resolución y decreto de inscripción de La Gaya Ciencia, S. A. en el Registro de Empresas Editoriales», 25 de junio de 1974, Madrid.

125. AGA, Cultura, 62/6485, 115/7, "Carta de Rosa Regás al Director General de Cultura, Ricardo de la Cierva", 5 de julio de 1974, Barcelona.

126. AGA, Cultura, 62/06468, 98/10, “Carta de José María Castellet al Director General de Cultura Popular», 22 de enero de 1971, Barcelona. 
En esta ocasión la consecución del número de inscripción no fue tan inmediata, pero sí se reanudaron los trámites necesarios, y el proceso concluyó el 13 de noviembre de 1972, cuando Edicions 62 consiguió el número de inscripción 1063/72 del Registro de Empresas Editoriales ${ }^{127}$.

En contraste con esta estrategia, nos encontramos con el expediente de Cuadernos para el Diálogo (EDICUSA). Los propietarios de esta editorial optaron por otro camino que la propia ley franquista amparaba. Cuadernos para el Diálogo había solicitado la inscripción en el Registro de Empresas Editoriales el 5 de abril de 1967128, y pese a haber sido concedida su inscripción en el Registro de Empresas Periodísticas, tres años después no había noticias del Registro de Empresas Editoriales. Sus propietarios, amparados por el artículo 94.1 de la Ley de Procedimiento Administrativo, decidieron "denunciar la mora»" ${ }^{129}$. La Ley de Procedimiento Administrativo en su artículo 94.1 señala:

cuando se formulase alguna petición ante la Administración y ésta no notificase su decisión en el plazo de tres meses desde la petición, podrá considerar desestimada su petición, al efecto de deducir frente a esta denegación presunta, el correspondiente recurso administrativo o jurisdiccional, según proceda, o esperar la resolución expresa de su petición

y en su artículo 61:

no podrá exceder de seis meses el tiempo que transcurra desde el día en que se inicie un procedimiento administrativo hasta aquel en que se dicte resolución, al no mediar causas excepcionales, debidamente justificadas, que lo impidieren, las cuales se consignarán en el expediente por medio de diligencia firmada por el Jefe de la Sección correspondiente.

Además, la ley señala que, en caso de transcurrir los seis meses y no estar justificado su retraso, los interesados podrán interponer un recurso para que la autoridad correspondiente inicie un expediente disciplinario para determinar el funcionario o funcionarios responsables, y valorar si es oportuno imponerles sanciones. En el documento interno del Registro que se conserva sobre dicha denuncia, aparece manuscrito: «El expediente E.D.I.C.U.S.A. tiene hecha la resolución positiva ya que jurídicamente está en regla (su detención obedece a razones políticas). Concedido y aprobado por el Sr. Ministro» ${ }^{130}$. Tres meses después, habiendo completado la documentación solicitada

127. AGA, Cultura, 62/06468, 98/10, «Resolución y decreto de inscripción de Edicions 62 en el Registro de Empresas Editoriales", 13 de noviembre de 1972, Madrid.

128. AGA, Cultura, 62/06457, 87/8, «Instancia de inscripción en el Registro de Empresas Editoriales de Cuadernos para el Diálogo", 29 de marzo de 1967, Barcelona.

129. AGA, Cultura, 62/06457, 87/8, «Escrito denunciando la mora elevado a la superioridad, Editorial Cuadernos para el Diálogo, S. A., EDICUSA, al Ministro de Información y Turismo», 9 de abril de 1970, Madrid.

130. AGA, Cultura, 62/06457, 87/8, "Documentación interna”, abril de 1970. 
por el Ministerio, Cuadernos para el Diálogo conseguía el número de inscripción 911/70 en el Registro de Empresas Editoriales ${ }^{131}$.

Una vez conseguido el número de inscripción en el Registro, los expedientes de Enlace conservados en el archivo nos muestran que las editoriales seguían siendo investigadas por el Ministerio. Esta vez, el objeto de la investigación no era tanto sus fundadores o las personas que participaban de la empresa, como su línea editorial y el cumplimiento del plan editorial expuesto en la solicitud de inscripción. Existe una excepción a esta afirmación: es el caso de Barral Editores, que recibió su número de registro 699/67 en noviembre de 1967 y, entre los años 1971 y 1972, sus promotores y participantes fueron objeto de una investigación que puso el foco sobre Carlos Barral e Yvonne Hortet y los nuevos accionistas ${ }^{132}$.

Existe un modelo de documento, que es una relación de las obras denegadas y de las sometidas a silencio administrativo, que aparece en las editoriales que estaban bajo la investigación del Ministerio. Este es el caso de Lumen, cuyo documento puede servirnos como ejemplo para reflejar el tipo de información que contenían estos informes:

«Obras Denegadas - 1969:

5296 - 69: El último combate de Lenin, Noshé Lewin, 12 de junio de 1969.

10763 - 69: Otro país, James Baldwin, 2 de noviembre de 1969.

Silencio administrativo - 1969:

4546 - 69: Los comics en España, Luis Gasca, 6 de noviembre de 1969.

Obras Denegadas - 1970:

7472 - 69: Discurso sobre Vietnam, Peter Weiss, 7 de enero de 1970.

10763 - 69: Otro país, James Baldwin, 8 de enero de 1970.

1018 - 70: Memorias de una adolescente católica, Mary McCarthy, 9 de marzo de 1970.

5864 - 70: La máquina silenciosa, William S. Burroughs, 17 de junio de 1970.

5866 - 70: Amar en Barcelona, Román Gubern, 6 de julio de 1970.

7408 - 70: ¿Por qué estamos en Vietnam?, Norman Mailer, 20 de julio de 1970»133.

También fue el caso de la editorial Fontanella ${ }^{134}$ y de Barral Editores ${ }^{135}$. Pero el caso más conocido es, sin duda, el de la Editorial Estela. Fundada en 1958 ${ }^{136}$, inició su

131. AGA, Cultura, 62/06457, 87/8, «Resolución y decreto de inscripción de Cuadernos para el Diálogo en el Registro de Empresas Editoriales», 23 de julio de 1970, Madrid.

132. AGA, Cultura, 62/06440, 70/2, "Informes y antecedentes político-sociales de Carlos Barral e Yvonne Hortet", 10 de marzo de 1971, Madrid; AGA, Cultura, 62/06440, 70/2, "Informe confidencial sobre Barral Editores", 1971, Madrid; AGA, Cultura, 62/06440, 70/2, "Informe sobre los accionistas de Barral Editores», 23 de abril de 1971, Madrid.

133. AGA, Cultura, 62/06391, 21/5, "Obras denegadas y mantenidas en silencio administrativo de Editorial Lumen", 1970, Madrid.

134. AGA, Cultura, 62/06408, 38/6, "Obras denegadas y mantenidas en silencio administrativo de Fontanella", 1970, Madrid.

135. AGA, Cultura, 62/06440, 70/2, "Informe confidencial sobre Barral Editores», 1971, Madrid.

136. AGA, Cultura, 62/06427, 57/5, "Escritura de Constitución ante Notario de Estela, S.A.", 13 de febrero de 1958, Barcelona. 
solicitud para inscribirse en el Registro de Empresas Editoriales el 31 de marzo de 1967, con un plan editorial centrado en obras teológicas y religiosas ${ }^{137}$. El 27 de marzo de 1968 consiguió el número de inscripción 568/68 en el Registro de Empresas Editoriales, sin ningún impedimento. Sin embargo, en 1970 el libro religioso entró en crisis ${ }^{138}$ y Estela decidió dar un giro a su línea editorial y publicar libros con mayor rentabilidad. En 1971, los funcionarios del Registro elaboraron un informe manuscrito donde hacen constar estos cambios en la línea editorial:

"La Historia del Primero de Mayo», de M. Dommanget, exaltación de la ideología marxista.

"Literatura y Arte Nuevo en Cuba», exaltación de ideología castrista.

"Los que nunca opinan", de Francisco Candel, fuerte contenido subversivo e incitación a la revolución social.

Todas ellas denunciadas a la autoridad y alguno con expediente administrativo.

[Reverso:]

Espiritualidad y educación adultos y padres (unos educadores)

Infantiles, bíblicos, litúrgicos

Formación religiosa infantil» ${ }^{339}$.

En mayo de 1971, el Jefe de la Sección de Ordenación Editorial se dirigió al Director de Cultura Popular, elaborando un informe con los distintos motivos que justificaban la cancelación del número de inscripción de Estela. Entre ellos constaba un resumen de la actividad editorial de Estela durante los años 1970 y 1971, con el total de las obras presentadas a censura previa, las denegadas, las denunciadas y las sometidas a silencio administrativo. Este informe llegaba a la siguiente conclusión:

[...] Estos datos demuestran que la Editorial ESTELA ha dejado de atenerse al plan editorial declarado en el expediente de inscripción en el Registro de Empresas Editoriales. La índole de las numerosas obras reseñadas significa, por sí misma, una vulneración de los límites señalados a la libertad de expresión por el artículo $2^{\circ}$ de la Ley de Prensa e Imprenta y tiende, por otra parte, a «deformar la opinión pública» en materias directamente relacionadas con los fundamentos ideológicos reconocidos en las Leyes Fundamentales del actual Estado español. Por todo ello, el Jefe de la Sección que suscribe eleva a V. I. este informe, por si tiene a bien proponer la cancelación de la inscripción de la citada editorial ESTELA en el Registro de Empresas Editoriales [...] $]^{140}$.

137. AGA, Cultura, 62/06427, 57/5, «Instancia de inscripción en el Registro de Empresas Editoriales de Editorial Fontanella", 31 de marzo de 1967, Barcelona; AGA, Cultura, 62/06427, 57/5, «Propuesta de plan editorial», 1967, Barcelona.

138. Cisquella, Georgina; ERviti, José Luis y Sorolla, José A.: La represión cultural en el franquismo..., p. 78.

139. AGA, Cultura, 62/06427, 57/5, «Documento interno", 1971, Madrid.

140. AGA, Cultura, 62/06427, 57/5, «Informe sobre la Editorial Estela del Jefe de la Sección de Ordenación Editorial al Director General de Cultura Popular y Espectáculos», 27 de mayo de 1971, Madrid. 
Tras este informe, el propio Ministerio elaboró un documento interno explicando el procedimiento a seguir para cancelar la inscripción de una editorial y cuáles eran los posibles recursos que podían interponerse ${ }^{141}$. El 19 de mayo de 1971, se emitió la resolución de cancelación de la inscripción de número 568/68:

Por Resolución de esta fecha el Excmo. Señor Ministro de este Departamento ha dispuesto la cancelación de la inscripción Número 568 del Registro de Empresas Editoriales, correspondiente a la Empresa EDITORIAL ESTELA, S. A. por tener lugar en dicha inscripción los supuestos del apartado segundo del artículo 29 de la vigente Ley de Prensa e Imprenta.

Lo que le comunico para su conocimiento y efectos.

Madrid, 29 de mayo de 1971.

EL DIRECTOR GENERAL DE CULTURA POPULAR Y ESPECTÁCULOS ${ }^{142}$.

En el desarrollo de dicha resolución, se especificaba que la Editorial Estela "presentó un proyecto de edición de obras de carácter fundamentalmente dedicado a la espiritualidad, formación religiosa, bíblicas, litúrgicas, normas educativas, infantiles, etc.». Sin embargo, se habían publicado

una serie de obras que sobrepasan los límites que impone el artículo segundo de la Ley de Prensa e Imprenta, según se acredita en los datos suministrados por el Negociado de Lectorado, como son los referentes a los siguientes títulos: La Historia del Primero de Mayo, de ideología marxista; Literatura y Arte Nuevo, exaltadores del castrismo; Los que nunca opinan, de Francisco Candel, de fuerte contenido subversivo e incitador de la revolución social; todas ellas denunciadas a la Autoridad judicial u objeto de expediente administrativo sancionador.

Además, pese a la obligatoriedad de comunicar semestralmente los cambios habidos en la editorial, Estela no había presentado «ninguna modificación o ampliación del plan editorial, a efectos de constancia en el citado Registro", por tanto, se acordaba la cancelación de la inscripción en el Registro de Empresas Editoriales ${ }^{143}$.

Una vez recibida la resolución por parte del Ministerio, desde la editorial Estela alegaron que dicha resolución era nula y, por tanto, quedaba sin efecto al no cumplir el procedimiento establecido por la Ley de Prensa e Imprenta para la cancelación de las inscripciones ${ }^{144}$. Además, los editores de Estela realizaron un informe dirigido al

141. AGA, Cultura, 62/06427, 57/5, "Documentación interna del Ministerio de Información y Turismo", 1971, Madrid.

142. AGA, Cultura, 62/06427, 57/5, «Resolución de cancelación de la inscripción de la Editorial Estela en el Registro de Empresas Editoriales», 29 de mayo de 1971, Madrid.

143. AGA, Cultura, 62/06427, 57/5, "Resolución de cancelación de la inscripción de la Editorial Estela en el Registro de Empresas Editoriales», 29 de mayo de 1971, Madrid.

144. AGA, Cultura, 62/06427, 57/5, "Reclamación de Ramón Ribó Martí, Editorial Estela», 22 de junio de 1971, Madrid. 
Subdirector General de Cultura Popular y Espectáculo sobre el impacto que tendría el cierre de la editorial, incidiendo en que la cancelación de la inscripción se trataba de una "medida política»"145. Decidieron dar la batalla por la vía judicial interponiendo un recurso por la vía contencioso-administrativa, y el Ministerio, temiendo el éxito de éste, ofreció a los editores registrarse nuevamente cambiando el nombre de la empresa ${ }^{146}$. El 25 de enero de 1972, Estela comunica su decisión de retirar el recurso de alzada interpuesto ante el Consejo de Ministros ${ }^{147}$.

Muy diferente fue lo que le ocurrió a la editorial de Jorge Herralde, Anagrama. El 20 de febrero de 1968, Jorge Herralde presentó una instancia ante el Registro para legalizar la Editorial Crítica ${ }^{148}$. Dos meses después, consiguió el número de registro ${ }^{149}$. Sin embargo, el 25 de octubre de 1968, Jorge Herralde informó al Registro de Empresas Editoriales de que "la empresa girará la denominación comercial de «Editorial Anagrama", ya que la denominación primeramente elegida — "Editorial Crítica» — no ha podido inscribirse como Marca en el Registro Industrial por estar ya registrada ${ }^{150}$. Dicho cambio fue aceptado, y la empresa quedó inscrita bajo su nombre actual, Anagrama.

Para finalizar, cabe destacar que los expedientes del Registro de Empresas Editoriales nos permiten reconstruir las redes editoriales que se fueron tejiendo entre las editoriales de Distribuciones Enlace (Magin Tusquets i Terrats era el gerente de Lumen y el principal accionista de Tusquets; Oriol Bohigas Guardiola era accionista en La Gaya Ciencia y pertenecía al Consejo de Administración de Edicions 62; Rosa Regás mantenía 56 acciones en Barral Editores...), así como comprender el contexto histórico que determinaba el desarrollo de estas editoriales, y las herramientas con las que contaba el Régimen para controlar el desarrollo cultural y editorial de la sociedad española.

\section{CONCLUSIONES}

El franquismo fue capaz de valorar a los editores como agentes culturales con incidencia política y social. Mediante la Ley de Prensa e Imprenta de 1966, el Régimen

145. AGA, Cultura, 62/06427, 57/5, "Informe sobre la situación de la Editorial Estela», 1 de julio de 1971, Barcelona.

146. Cisquella, Georgina; ERviti, José Luis y Sorolla, José A.: La represión cultural en el franquismo..., p. 88.

147. AGA, Cultura, 62/06427, 57/5, «Instancia retirando el recurso interpuesto ante al Consejo de Ministros", 25 de enero de 1972, Barcelona.

148. AGA, Cultura, 62/06427, 57/1, «Instancia de inscripción en el Registro de Empresas Editoriales de Editorial Crítica", 20 de febrero de 1968, Barcelona.

149. AGA, Cultura, 62/06427, 57/1, "Resolución y decreto de inscripción de Editorial Crítica en el Registro de Empresas Editoriales», 8 de abril de 1968, Madrid.

150. AGA, Cultura, 62/06427, 57/1, "Informe sobre las modificaciones sufridas en la editorial", 25 de octubre de 1968, Barcelona. 
perfeccionó sus herramientas para frenar el impacto que la actividad editorial causaba en la sociedad española. Institucionalizó y regularizó el Registro de Empresas Editoriales como mecanismo de censura editorial, para centrar su control sobre las publicaciones en la figura de los editores y condicionar el desarrollo editorial.

Tras el estudio de los expedientes de la Distribuidora Enlace que se conservan en el Archivo del Instituto Nacional del Libro Español, en el Registro de Empresas Editoriales, podemos afirmar que la Ley de Prensa e Imprenta no supuso una apertura para la producción cultural, ni una medida liberalizadora por parte del Régimen. Por el contrario, centró sus investigaciones en los productores del libro, manteniendo la censura previa como condición para la autorización de las publicaciones, y creando nuevos entramados burocráticos, como el Registro de Empresas Editoriales, a los que debían enfrentarse los editores para conseguir sacar adelante sus empresas culturales. Bajo la apariencia de un proceso reglamentado para formalizar la inscripción en el Registro de Empresas Editoriales y conseguir el número de inscripción imprescindible para publicar, se escondía toda una estrategia de control político sobre los editores, que desembocó en el cese de la actividad de algunas editoriales por los antecedentes políticos de sus promotores.

Esta investigación demuestra la necesidad de ampliar el campo de estudio de la censura. Se han realizado multitud de proyectos sobre la censura en las obras y libros, sin embargo, nuestra propuesta consiste en ampliar estas investigaciones hacia la censura editorial y las herramientas que el Régimen implementó para desarrollar esta práctica y sus consecuencias. Para ello, es fundamental dotar de valor e importancia a los archivos y fuentes documentales en el estudio de la historia editorial. Es imprescindible la utilización de estos fondos documentales para estudiar y reconstruir las trayectorias de las editoriales y de sus editores, las redes culturales que tejieron y las estrategias que desarrollaron para enfrentarse a los obstáculos de la censura.

El franquismo se enfrentó a los proyectos culturales de corte democrático desarrollando herramientas que buscaban acotar los espacios de libertades donde se desenvolvían estos proyectos y, específicamente, detener su impacto limitando sus canales de trasmisión. Estas políticas contraculturales generaron como respuesta la creación de redes de alianzas entre las editoriales, que fortalecieron el desarrollo cultural de la sociedad española, forjando espacios desde los que cuestionar la hegemonía cultural del Régimen franquista. 